\title{
ALTERAÇÕES NO FORMATO DA REPORT AGEM NO PROGRAMA CHAMADA GERAL, DA GAÚCHA, DE PORTO ALEGRE: dos anos 1980 até a contemporaneidadel
} CHANGES IN THE FORMAT OF THE REPORT IN THE PROGRAM CHAMADA GERAL OF GAÚCHA, FROM PORTO ALEGRE: from the 1980 s to the contemporary

\author{
Léo Henrique SABALLA JÚNIOR² \\ Luiz Artur FERRARETTO ${ }^{3}$
}

Universidade Federal do Rio Grande do Sul | Brasil

\begin{abstract}
Resumo
Busca compreender as alterações na forma de apresentação da reportagem radiofônica no programa Chamada Geral, da Gaúcha, de Porto Alegre, na passagem da fase de segmentação para a de convergência. Do ponto de vista histórico, baseia-se na periodização defendida por Ferraretto (maio-ago. 2012). Parte, ainda, das ideias de modo de emissão autentificante, proposta por Jost (2001), e de efeito de real, elaborada por Motta (2013), trabalhando-as em paralelo com a descrição das facetas do comunicador na contemporaneidade (FERRARETTO, 2014a). Como corpus, utiliza edições parciais e integrais de programas das décadas de 1980, 1990, 2000 e 2010. Dessa maneira, identifica a passagem de um modelo de reportagem gravada e montada para outro integralmente ao vivo e mais coloquial.

\section{Palavras-chave}

Reportagem; Gaúcha; Chamada Geral; Convergência; Autentificação.

\section{Abstract}

It seeks to understand the changes in the radio report is presented in the program Chamada Geral, from Gaúcha, from Porto Alegre, in the transition from segmentation to convergence. From the historical point of view, it is based on the periodization defended by Ferraretto (May-Aug. 2012). It also starts from the ideas of an authenticated mode of emission, proposed by Jost (2001), and of real effect, elaborated by Motta (2013), working them in parallel with the description of the facets of the communicator in contemporary (FERRARETTO, 2014a). As a corpus, it uses partial and integral editions of programs from the 1980s, 1990s, 2000s and 2010s. Thus, it identifies the passage from one recorded and assembled model of reportage to another entirely live and more colloquial.

Keywords

Report; Gaúcha; Chamada Geral; Convergence; Authentication.
\end{abstract}

RECEBIDO EM 30 DE MARÇO DE 2020

ACEITO EM 11 DE MAIO DE 2020

\footnotetext{
${ }^{1}$ Baseado em trabalho apresentado no GP Rádio e Mídia Sonora, no $41^{\circ}$ Congresso Brasileiro de Cências da Comunicação, em 2018.

2 Mestre pelo Programa de Pós-graduação em Comunicação e Informação da Universidade Federal do Rio Grande do Sul. Contato: saballa@gmail.com.

3 Professor do Programa de Pós-Graduação em Comunicação e Informação da Universidade Federal do Rio Grande do Sul, Porto Alegre, RS. Responsável pelo Núcleo de Estudos de Rádio, grupo de pesquisa certificado junto ao Conselho Nacional de Desenvolvimento Científico e Tecnológico (CNPq). Contato: luiz.ferraretto@ufrgs.br.
}

João Pessoa - Brasil | ANO 7 VOL.7 N.1 | JAN./JUN. 2020 | p. 19-38

Revista Latino-americana de Jornalismo | ISSN 2359-375X

Programa dePós-Graduação em Jornalismo - UFPB

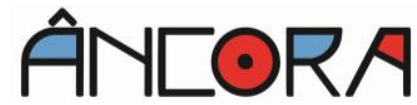




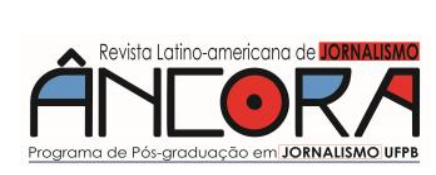

Léo Henrique SABALLA JÚNIOR - Luiz Artur FERRARETTO

\section{Introdução}

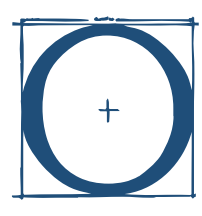

ano é 1992. O jornalista Oziris Marins, repórter da Gaúcha4, recorre a um orelhão para conseguir transmitir uma notícia ao vivo. A pedido do apresentador no estúdio, faz enquetes com pessoas que passam, chamando-as para que se aproximem e compartilhem suas opiniões com os ouvintes (MARINS, 20 jan. 2017). Doze anos depois, em 2014, na mesma rádio, o repórter Mateus Ferraz sai da redação para cobrir uma ocorrência policial. Vai munido de dois telefones celulares, um bastão para afixar um deles e um equipamento de transmissão de áudio com qualidade semelhante à de estúdio, o Access, que usa conexão via protocolo de internet e é fabricado pela estadunidense Comrex. Ferraz registra uma altercação entre os protagonistas. Entra ao vivo e, simultaneamente, grava imagens com um smartphone: "Entrou até no Jornal Nacional, na Globo. Se eu não tivesse gravado, ninguém iria ver aquilo" (FERRAZ, 16 de fev. 2017).

Desde a introdução do celular, em 1990, e da internet comercial, no ano de 1995, a entrada ao vivo em rádios foi facilitada graças à mobilidade e à qualidade de áudio proporcionada por aprimoramentos relacionados a essas tecnologias. Esse tipo de inserção já existia antes, mas, na década de 2010, tornou-se a forma predominante no Chamada Geral, principal radiojornal da Gaúcha, de Porto Alegre. Aqui, portanto, procura-se descrever o porquê de tal alteração, usando como recurso de pesquisa a comparação entre trechos de programas de diferentes períodos. Antes de seguir nessa linha de raciocínio, é necessário contextualizar o processo que valida essa mudança como significativa em termos de influência sobre outras emissoras.

Fundada em 1927, a Gaúcha possui uma programação dedicada ao jornalismo 24 horas por dia, liderando há cinco anos a audiência geral na Grande Porto Alegre (ZERO HORA, 14-15 mar. 2020, p. 43). A emissora é

\footnotetext{
${ }^{4}$ Adotou-se apenas a denominação "Gaúcha" - e não "Rádio Gaúcha" -, reproduzindo atitude da emissora em seu reposicionamento como veículo multiplataforma.
}

João Pessoa - Brasil | ANO 7 VOL.7 N.1 | JAN./JUN. 2020 | p. 19-38 
controlada pelo Grupo RBS, da família Sirotsky. Desde 1983, opera no formato talk and news, em que, segundo Luciano Klöckner (1997, p. 23-24), "as notícias são transmitidas de forma direta e dinâmica (news), contribuindo para que o ouvinte capte imediatamente a informação. A seguir, são comentadas e discutidas (talk) nos espaços específicos (comentários e programas)". Este formato é uma mistura do all-news- modo exclusivo de notícias - com all-talk - preponderante na conversa (FERRARETTO, 2014b, p. 65).

O Chamada Geral estreou em meados de 1970, ficando fora do ar entre 1981 e 1984. Em sua fase inicial, ocupava a faixa das 18 às $18 \mathrm{~h} 30$. Quando retornou dentro do projeto de reposicionamento da Gaúcha como talk and news, passou a ser transmitido das $17 \mathrm{~h} 05$ às $17 \mathrm{~h} 55$. Em dezembro de 1990, ganhou uma edição matutina, das 11 às $11 \mathrm{~h} 55$ e, em maio de 2012, começou a contar com uma noturna, das $23 \mathrm{~h}$ à $0 \mathrm{~h}$, descontinuada em março de 2015.

Para a análise pretendida, faz-se necessário estabelecer o que se compreende como radiojornal e reportagem. A respeito do primeiro, observase que "[...] corresponde a uma versão radiofônica dos periódicos impressos, reunindo várias formas jornalísticas (boletins, comentários, editoriais, seções fixas - meteorologia, trânsito, mercado financeiro... - e até mesmo entrevistas)", assumindo-se o predomínio da reportagem nesse tipo de noticiário (FERRARETTO, 2014b, p. 73).

Tem-se claro também que o trabalho do repórter éa base do processo radiojornalístico (PORCHAT, 1989, p. 49), com o profissional procurando se esforçar ao máximo para ouvir todos os lados envolvidos (BARBEIRO; LIMA, 2003, p. 44). A respeito, acrescenta McLeish (2001, p. 77): "Nada deve ser transmitido sem que os fatos tenham sido verificados duas vezes, não por ouvir dizer ou por alguma sugestão, mas com total confiabilidade. 'Retorne à fonte' é um ditado muito útil". Conforme Klöckner (2006, p. 89), as 


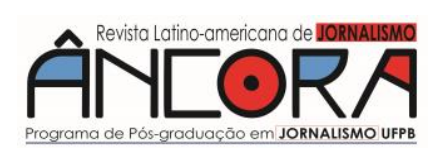

Léo Henrique SABALLA JÚNIOR - Luiz Artur FERRARETTO

reportagens dividem-se em (1) ao vivo, (2) gravadas e (3) uma mescla de ambas. Ao fazer a gravação, o repórter, geralmente, obtém um material que precisa passar por edição. Já quando está ao vivo, é submetido a provas a todo o momento, como a exigência de "rapidez mental e verbal para transmitir o fato enquanto o observa, vasto vocabulário, facilidade de exposição, dotes de improvisação e o mais importante: um acentuado senso de ética profissional" (PORCHAT, 1989, p.43).

Ao propor uma recuperação da trajetória da reportagem no Chamada Geral, ampara-se no que diz Michael Schudson (1993) sobre os estudos de comunicação por um viés histórico. A reflexão situa-se no âmbito do que o autor chama de história das instituições, linha que busca responder à pergunta "de que modo se desenvolveu esta ou aquela instituição de comunicação de massa?" (SCHUDSON, 1993, p. 215). No entanto, atendendo ao alerta do pesquisador sobre o reducionismo dessa perspectiva, procurase uma aproximação com a história propriamente dita, preocupada com o que "a comunicação nos diz sobre a sociedade e o que a sociedade nos conta da comunicação ou ambas ao mesmo tempo" (SCHUDSON, 1993, p. 214). Assim, analisa-se o objeto deste artigo "em relação à organização e às utilizações sociais das tecnologias em cenários históricos específicos", considerando as próprias tecnologias "como práticas sociais e culturais" (SCHUDSON, 1993, p. 227). É justamente em torno dessas que orbitam mudanças no trabalho do repórter, preocupação central desta reflexão.

Faz-se necessário considerar a convergência, marcada pelo fluxo de conteúdos através de múltiplas plataformas, em que todo o consumidor é cortejado e a circulação de conteúdos depende da participação sua e dos demais. Como observa Henry Jenkins (2006, p. 28), vive-se imerso, desde o final do século 20, em uma cultura da convergência, processo não restrito apenas ao âmbito da tecnologia: "A convergência não ocorre por meio de aparelhos, por mais sofisticados que venham a ser. A convergência ocorre 
dentro dos cérebros de consumidores individuais e em suas interações sociais com outros".

Considera-seo aqui descrito como um processo posicionado em duas fases da história do rádio brasileiro: (1) a de segmentação, iniciada no final da década de 1950, estendendo-se até os primeiros anos do século 21 , e caracterizada pela divisão do mercado em nichos de audiência e anunciantes, desenvolvendo-se para atendê-los programações centradas na figura do comunicador, aquele a simular, pendendo para coloquial, uma conversa com o ouvinte; e (2) a de convergência, que vai de meados da década de 1990, chegando aos dias de hoje, e se delineando pela redefinição do meio rádio para além das ondas hertzianas, com intenso incentivo à participação do público (FERRARETTO, maio-ago. 2012). Essa transição da segmentação para a convergência coincide com a consolidação da multiplicidade da oferta, denominação proposta por Valério Brittos (1999) para descrever, de início, o novo período vivido pela televisão face ao surgimento da distribuição de conteúdo por cabo. Posteriormente, o próprio autor ampliaria esta noção em direção a outros meios, inclusive para o rádio (BRITTOS, 2002). Deste modo, assume-se que, na contemporaneidade, predominam situações nas quais cada conteúdo concorre com todos os outros, independentemente de terem ou não finalidade massiva.

Dando conta de tais transformações, é oportuna a ideia de rádio expandido (KISCHINHEVSKY, 2016), descritiva da extrapolação da base tecnológica original do meio e associada ao uso das mídias sociais pelas emissoras e pelos seus profissionais. A atuação da Gaúcha exemplifica bem tal transbordamento. Seja da rua ou dentro da redação, o ao vivo, - ao microfone e pelo serviço Live do Facebook - passou a ser uma prioridade, não necessariamente apenas para a divulgação de fatos que estejam acontecendo naquele momento. Segundo o então apresentador e editor- 


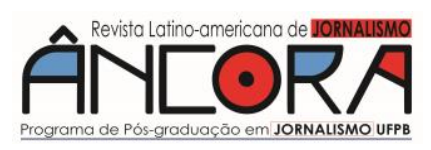

Léo Henrique SABALLA JÚNIOR - Luiz Artur FERRARETTO

chefe da emissora, Daniel Scola (12 jan. 2017), "a intenção é passar uma sensação ao ouvinte de um permanente breaking news".

Na sequência, após breves considerações sobre a reportagem radiofônica e o modo de emissão autentificante (JOST, 2001), realiza-se uma análise comparativa para demarcar as diferenças entre a apresentação desse tipo de conteúdo no programa Chamada Geral nas fases de segmentação e de convergência. Assume-se que "a comparação aparece como sendo inerente a qualquer pesquisa no campo das ciências sociais, esteja ela direcionada para a compreensão de um evento singular ou voltada para o estudo de uma série de casos previamente escolhidos" (SCHNEIDER; SCHMITT, 1998, p.49). Na busca por semelhanças e diferenças, parte-se da estrutura tradicional da reportagem como descrita, ainda na fase de segmentação, por Ferraretto e Kopplin (1992, p. 31-32) e apresentada na Tabela 1.

Tabela 1: Elementos básicos da reportagem radiofônica

\begin{tabular}{|c|c|}
\hline CABEÇA & $\begin{array}{c}\text { Introdução que resume o assunto a ser } \\
\text { desenvolvido no texto. Corresponde ao lide }{ }^{5} \\
\text { da imprensa escrita. }\end{array}$ \\
\hline ILUSTRAÇÃO6 & $\begin{array}{c}\text { É a entrevista realizada com a fonte e que } \\
\text { ilustra reportagem. }\end{array}$ \\
\hline ENCERRAMENTO & $\begin{array}{c}\text { Informação complementar. Em geral, é } \\
\text { acompanhada da identificação do } \\
\text { entrevistado. }\end{array}$ \\
\hline ASSINATURA & $\begin{array}{c}\text { Local de onde a informação é transmitida e } \\
\text { identificação do repórter. Por vezes, inclui o } \\
\text { nome do programa, o de um patrocinador } \\
\text { ou um slogan da emissora. }\end{array}$ \\
\hline
\end{tabular}

Fonte: FERRARETTO; KOPPLIN, 1992, p. 32

\footnotetext{
${ }^{5} \mathrm{~A}$ abertura do texto noticioso, aquela que resume os principais dados a respeito do tema abordado e tem a função de fisgar a atenção do público.

${ }^{6}$ Em obras posteriores (FERRARETTO, 2014), como sinônimo de ilustração, aparece a palavra "sonora", originária do jargão profissional de televisão, mas assimilada pelo rádio.
} 
Como não é habitual, nas emissoras, o arquivamento sistemático desse tipo de conteúdo, a análise usou um corpus algo assistemático ${ }^{7}$ dentro do que foi possível localizar: quatro programas gravados na íntegra e referentes às edições da manhã dos dias 26 de fevereiro de 1993, 28 de fevereiro de 2007 e 26 de fevereiro de 2018 e um fragmento de uma edição de 30 de julho de 1986.

\section{A reportagem e o modo de emissão autentificante}

A análise aqui realizada dá sequência a uma série de reflexões a respeito da simulação da conversa em rádio e de sua amplificação pelas redes sociais, "extensões ao natural do diálogo proposto" (FERRARETTO, 2016, p. 159). Destaca-se que: "O repórter conversa com âncoras e comentaristas e, em meio à interação gerada no estúdio e fora deste nas redes sociais, são inseridos os trechos previamente preparados de seu trabalho" (FERRARETTO, 2017, p. 160). Tal fluxo de informações entre o profissional que se encontra no palco de ação do fato e os que estão no estúdio auxilia na simulação de uma conversa com o ouvinte. Para compreender como a participação ao vivo reforça a ideia de veracidade da narrativa do repórter, lança-se mão de formulações de Jost (2001). O pesquisador francês propõe um modelo para analisar o conteúdo televisivo contemplando diferentes modos de emissão. Sua formulação já foi anteriormente aplicada à programação radiofônica (FERRARETTO, 2014a). Do exposto por Jost, interessa o chamado modo autentificante. Esse engloba emissões que "possuem asserções verdadeiras sobre o mundo, fornecendo informações para ampliar o conhecimento e que se destacam, em última instância, como um exercício da prova" (JOST, 2001, p. 19). Cabe observar que, na contemporaneidade, todos se tornam, em certa medida, comunicadores,

\footnotetext{
${ }^{7}$ A própria Gaúcha não possui esse tipo de material arquivado na íntegra. O fragmento citado pertence ao seu acervo. Os programas são do arquivo pessoal do professor Luiz Artur Ferraretto, tendo sido usados em suas aulas ao longo do tempo.
}

João Pessoa-Brasil | ANO 7 VOL.7 N.1 | JAN./JUN. 2020 | p. 19-38 


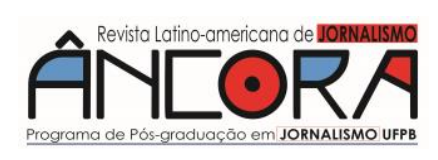

Léo Henrique SABALLA JÚNIOR - Luiz Artur FERRARETTO

incluindo o repórter. Para delimitar a relevância, nesse sentido, da identificação de tais emissões como autentificantes, cabe destacar:

\begin{abstract}
Uma das maneiras pela qual a televisão atesta que um acontecimento é real - característica compartilhada com o rádio é a simultaneidade entre a captação e a recepção. Se alguém, por vezes, considera passível de contestação o tema de uma emissão de um espetáculo, por convenção, reconhecido como irradiado em tempo real, é porque produtores e telespectadores concordaram que nele existe veracidade. Eu chamo isto de modo autentificante, e não apenas informativo. Para além das transmissões de notícias do mundo, de sua atualidade, identifica todos os programas que remetem a um discurso de realidade e que nós interpretamos sobre o eixo verdadeiro-falso. As transmissões ao vivo nos dão a impressão de acessar diretamente os acontecimentos, de ser testemunhas do mundo [...]. (JOST, 2001. p. 19).
\end{abstract}

Jost explica, ainda, que a audiência aceita como autêntica uma transmissão, admitindo que esta (a) propõe algo considerado válido; (b) expressa uma verdade profunda, um sentimento ou relato, como nos depoimentos e nas transmissões ao vivo em geral; e (c) possui a marca de um indivíduo, cuja autoridade não pode ser contestada, valorizando, por vezes, uma informação em razão da sua fonte. De acordo com Ferraretto (2014a, p. 64), estes fatores estão presentes na postura que o comunicador radiofônico assume nas emissões ao vivo.

Conforme Motta, são usadas estratégias para provocar um efeito de real, fazendo com que o público interprete a narrativa como uma verdade, "como se os fatos estivessem falando por si mesmo" (MOTTA, 2013, p. 199). Uma dessas, segundo o professor da Universidade de Brasília, é utilizar expressões que remetem ao momento presente, como "aqui" e "agora", por meio das quais também o hoje, o ao vivo e o on-line passam a ser valorizados: "Na afirmação radical do presente (a atualidade), o jornalismo constrói a sua versão de neutralidade e objetividade, reduzindo e encerrando tudo no momento atual" (MOTTA, 2013, p. 200).

Ainda dentro da reflexão em torno do modo autentificante, admite-se como importante, o papel do repórter como cúmplice da audiência. Isso 
ocorre, conforme entendimento de Piccinin, Etges e Borges ${ }^{8}$ (2015, f. 15), a partir da ideia de que o profissional pode expressar emoções ou opiniões e se humanizar, convocando a audiência para enfrentar o real, a partir de uma identificação entre o público e ele.

\section{A reportagem no Chamada Geralna fase de segmentação}

Na fase da segmentação, a inserção de reportagens no Chamada Geral ocorria nas formas gravada e ao vivo. É importante considerar como se dava o trabalho do profissional na coleta de informações e quais os recursos disponíveis:

[...] no final da década de 1980, (a) o repórter ia ao palco de ação do fato, coletava informações, ligava para a redação, passava dados que seriam convertidos em texto e entrava no ar, terminando, enfim, o seu trabalho; e (b) a tecnologia empregada englobava gravadores de fita, telefones fixos e unidades móveis com rádios em UHF para comunicação com a emissora e entrada ao vivo no ar (FERRARETTO, set.-dez. 2015, p. 226).

$\mathrm{Na}$ reportagem gravada, mais frequente até a consolidação da telefonia celular, o conteúdo seguia em geral a estrutura: cabeça + ilustração (entrevistas) + encerramento + assinatura. No caso de duas ou mais falas de uma fonte, o repórter inseria um texto de passagem entre essas. Já se tinha consciência sobre as limitações e vantagens do material editado. Na época, Maria Elisa Porchat (1989, p. 54) observa que, ao se optar por esse tipo de conteúdo: "Perde-se a instantaneidade e um pouco da espontaneidade, em troca de tempo e de uma forma aperfeiçoada, já que a gravação permite que cortes e correções sejam feitos". No ao vivo, a presença do entrevistado servia como suporte principal da narrativa do repórter, que dialogava com um protagonista, uma testemunha ou um especialista, todos obviamente relacionados ao tema abordado.

\footnotetext{
${ }^{8}$ Faz-se, aqui, transposição, para o rádio, de considerações a respeito do papel dos apresentadores nos programas $O$ mundo segundo os brasileiros, produção conjunta da Eyeworks e da Rede Bandeirantes de Televisão, e Não conta lá em casa, do Multishow, ambos analisados pelas autoras no artigo citado.
}

João Pessoa-Brasil | ANO 7 VOL.7 N.1 | JAN./JUN. 2020 | p. 19-38 


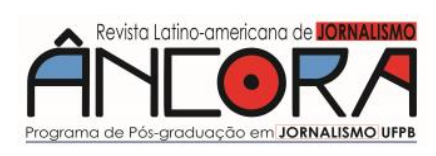

\section{Léo Henrique SABALLA JÚNIOR - Luiz Artur FERRARETTO}

Manual de redação editado em 1987 pela equipe da Gaúcha traz breves recomendações ao repórter. Apesar de pedir simplicidade na forma de transmitir a notícia, as orientações defendem uma linguagem mais formal, proibindo saudações ao apresentador nas participações ao vivo.

Os repórteres participam da programação de duas maneiras básicas:

1) Com boletim, em média com 1 minuto de duração, ao vivo ou gravado, assinando sempre "Gaúcha, a Fonte da Informação, local e nome, a seguir".

2) Com intervenções ao longo da programação, em diálogo ou não com apresentadores, sem tempo fixo.

Nos dois casos, o repórter não deve começar com qualquer tipo de saudação [...], entrando direto na notícia. (RÁDIO GAÚCHA, 1987, f. 21).

Dez anos depois, manual elaborado por Luciano Klöckner (1997) sugere, genericamente, informalidade ao repórter que entra ao vivo, além de alertar para a importância de fazer anotações para dar mais segurança. Traz ainda detalhadas orientações para a reportagem gravada.

1) Escute a fita com a entrevista anotando as falas principais.

2) Faça um Plano de Edição (cabeça, fala do entrevistado, assinatura do repórter).

3) $\mathrm{Na}$ hora de escrever, preferencialmente, não diga no texto (cabeça) o que o entrevistado vai falar. Desperte no ouvinte o interessa pela declaração do entrevistado.

4) O som deve ser de ótima qualidade. Se ele estiver ruim, só deve ir ao ar se o depoimento for muito importante.

5) Identifique o entrevistado, no início, no meio e no fim da matéria pelo cargo e pelo nome completo.

6) Repita, sinteticamente, a principal informação ao final da reportagem ou boletim. (KLÖCKNER, 1997, p. 72).

Ao consultar o fragmento de uma edição do Chamada Geral, de 30 de julho de 1986, encontra-se uma reportagem gravada, de Flávio Pereira, que aborda uma coligação partidária visando às eleições. Com duração de 2 minutos e 40 segundos, percebe-se que o repórter escreveu e gravou o texto. Há uma ilustração com duração de 1 minuto e 9 segundos. O âncora João Carlos Belmonte lê a cabeça da reportagem: "Pedessista garante que coligação com PDT visa aos interesses do Rio Grande do Sul. Os detalhes chegam através do repórter Flávio Pereira" (RÁDIO GAÚCHA, 30 jul. 1986). 
O repórter abre a reportagem: "O vice-líder do PDS na Assembleia Legislativa, deputado Sérgio Ilha Moreira, entregou hoje à direção estadual do partido um documento pelo qual ele consente que seu nome seja examinado como candidato a vice-governador" (RÁDIO GAÚCHA, 30 jul. 1986). O repórter utiliza um trecho de entrevista com o deputado citado captada com um gravador. Na sequência, volta a citar o nome do entrevistado: "Este foi o deputado Sérgio Ilha Moreira, vice-líder do PDS" (RÁDIO GAÚCHA, 30 jul. 1986).

No mesmo programa, há uma reportagem de Elódio Zorzetto, com 2 minutos e 9 segundos, também tratando da possibilidade de coligação entre o PDT e o PDS, além das articulações do PMDB. Há duas ilustrações: uma de 8 segundos, outra de 52 segundos. $O$ apresentador lê a cabeça: "Presidente do PDT gaúcho confirma acordo com o PDS para as próximas horas. No PMDB, é articulada a candidatura de Sinval Guazzelli para vice-governador. Repórter Elódio Zorzetto" (RÁDIO GAÚCHA, 30 jul. 1986). O repórter abre o texto: "Mais um dia de negociações para definir a aliança PDS e PDT. A assessoria jurídica dos dois partidos está reunida na assembleia analisando as recomendações legais para casos de coligação" (RÁDIO GAÚCHA, 30 jul. 1986). Mesmo que a reportagem trate de um fato que está acontecendo, o material é apresentado na forma gravada. É utilizada uma entrevista, captada usando gravador, com o presidente do PDT, Sereno Chaise, confirmando a aliança. Em seguida, o repórter completa com informações de uma outra reunião que estaria acontecendo. Mais uma vez, mesmo que o fato estivesse se desenrolando, a reportagem é apresentada na forma gravada. É utilizada ainda outra ilustração, a do deputado Lélio Souza, vice-presidente do PMDB, falando sobre o possível candidato a vice-governador pelo partido: "Não é preciso fazer grandes elocubrações, é o nome do ex-governador e exdeputado, Silval Guazzelli"(RÁDIO GAÚCHA, 30 jul. 1986). Por fim, o repórter 


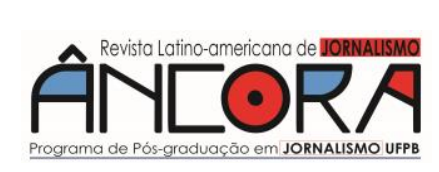

Léo Henrique SABALLA JÚNIOR - Luiz Artur FERRARETTO

diz que o PFL vai definir nos próximos dias a composição da chapa majoritária.

Sete anos depois, para o Chamada Geral - Primeira Edição de 26 de fevereiro de 1993, a repórter Nelcira Nascimento grava uma reportagem com duração de 2 minutos e 26 segundos, incluindo uma ilustração de 1 minuto e 50 segundos. $O$ assunto era uma reunião que ocorreria horas depois entre o então governador do Rio Grande do Sul, Alceu Collares, do PDT, e o senador gaúcho Pedro Simon, do PMDB: "Alceu Collares e o senador Pedro Simon se reúnem ainda hoje na praia de Rainha do Mar a fim de debater financiamentos para recuperação das estradas federais do estado e os projetos para reforma da constituição federal de 88 . No encontro, que acontece daqui a pouco, o governador vai entregar ainda ao senador uma carta destinada ao presidente Itamar Franco" (RÁDIO GAÚCHA, 26 fev. 1993). Em termos de fala da repórter, há ainda a assinatura: "Com informações sobre a reunião do governador Alceu Collares e o senador Pedro Simon, Nelcira Nascimento" (RÁDIO GAÚCHA, 26 fev. 1993). Entre esses trechos, aparece o entrevistado gravado, ocupando $68 \%$ do total da reportagem. Alceu Collares explica os motivos para a conversa com o senador: "Vou colocar esse problema das estradas, que ainda continuam nos enrolando, devemos colocar ainda o problema das nossas fronteiras [...], enfim, um conjunto de pleitos que o Rio Grande tem direito de ser beneficiado" (RÁDIO GAÚCHA, 26 fev. 1993).

Nos três exemplos, os repórteres, aparentemente, saíram da redação para a execução de seu trabalho. Em nenhum deles, por/se tratar de gravação, houve interação com o âncora no estúdio. Aparecem ainda alguns comentaristas fixos entre as reportagens.

Nos anos 1980 e 1990, as participações ao vivo eram limitadas pela tecnologia existente. O então coordenador de Jornalismo da Gaúcha, Claudio Moretto (20 jan. 2017), explica que os repórteres usavam equipamentos 
transceptores de mão ou em unidades móveis. A antena estava instalada na torre da RBS TV, no morro Santa Tereza. Segundo Francisco Paulo Bisogno (21 jan. 2017), responsável pelas transmissões externas da Gaúcha: "Funcionava, só que a qualidade de áudio era muito ruim". Uma alternativa era o uso de telefones privados ou públicos. Repórter na época, Oziris Marins (20 jan. 2017) conta que, no começo da década de 1990, costumava circular por órgãos públicos em busca de assuntos de interesse. Desses locais, suas participações eram feitas em telefones fixos. Quando estava na rua, por vezes, recorria ao uso de orelhões.

\section{A reportagem no Chamada Geralna fase de convergência}

Dois celulares, um bastão para afixar um deles e um equipamento pendurado por uma alça no ombro para transmissão de áudio. É assim que, na contemporaneidade, os profissionais da Gaúcha costumam atuar no palco de ação dos fatos. De acordo com o repórter Mateus Ferraz (16 de fev. 2017), um celular é usado para falar com a produção (por ligação telefônica ou por WhatsApp) e o outro para gravar imagens ou transmiti-las ao vivo. Além dessas facilidades tecnológicas, as reportagens no Chamada Geral são predominantemente ao vivo, por uma decisão editorial. É adotada não apenas para o relato do acontecimento urgente - um incêndio ou uma enchente, por exemplo -, mas também para assuntos rotineiros, com o objetivo de atrair a atenção da audiência. Conforme o editor-chefe da Gaúcha, Daniel Scola (12 jan. 2017): "O ouvinte, subliminarmente, pensa 'esses caras estão ao vivo, conversando comigo' É a charla9".

O próprio fazer jornalístico altera-se:

[...] no início dos anos 2010, (a) as novas possibilidades tecnológicas trouxeram mais funções ao jornalista, já não sendo suficiente planejar a execução de sua pauta exclusivamente para o rádio e devendo esta ser pensada também para a internet e as mídias sociais; e (b) tais funções passam a requerer revisão do

${ }^{9}$ Em espanhol, fala coloquial perante um público ou, simplesmente, a conversa. A expressão, por influência argentina e uruguaia, é muito usada no Rio Grande do Sul.

João Pessoa-Brasil | ANO 7 VOL.7 N.1 | JAN./JUN. 2020 | p. 19-38 


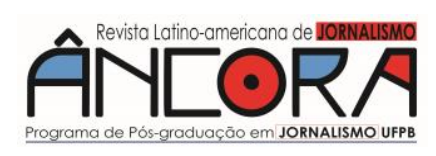

\section{Léo Henrique SABALLA JÚNIOR - Luiz Artur FERRARETTO}

que realmente é o seu trabalho, havendo tarefas relacionadas à produção de fotografias, textos e vídeos para veiculação on-line [...] (FERRARETTO, set.-dez. 2015, p. 226).

Com o repórter precisando expandir seu trabalho para a imagem e o texto em perfis de redes sociais, nos sites e nos aplicativos da emissora, não há mais tempo para edições de materiais. O mesmo Mateus Ferraz (16 fev.2017) conta que, na maioria das vezes, escreve textos apenas para publicá-los na internet, atribuição dos repórteres da Gaúcha desde 2013. Algo comum na fase de segmentação, o texto escrito e lido dá lugar ao exclusivamente falado:

Apurou uma informação e tem segurança sobre essa informação, vai para o ar imediatamente. Ter uma sonora é bom, mas passa a ser acessório. Prefiro um repórter que tenha uma boa informação, que entre ao vivo, mesmo que não tenha gravado um áudio com ninguém. Prefiro que vá para o ar imediatamente. (SCOLA, 12 jan. 2017).

No Chamada Geral - Primeira Edição de 26 de janeiro de 2017, o repórter Mateus Ferraz participa ao vivo com informações sobre a possibilidade de privatização do Banco do Estado do Rio Grande do Sul (Banrisul): "Assim como fez ontem em entrevista ao programa Gaúcha Atualidade, o secretário da Fazenda, Giovane Feltes, negou de forma enfática, hoje, que o governo federal tem imposto a privatização do Banrisul" (RÁDIO GAÚCHA, 26 jan. 2017). Em seguida, o âncora Antônio Carlos Macedo chama a repercussão em Brasília, estabelecendo um diálogo com o correspondente Guilherme Mazui:

\footnotetext{
Macedo - E aí em Brasília, o que se diz sobre isso, Guilheme Mazui?

Mazui - Macedo, conversei com o ministro da Casa Civil, Eliseu Padilha, e ele afirma que a decisão de vender o Banrisul é do governador José Ivo Sartori e da população do estado. Padilha explica que o tamanho do socorro financeiro negociado como o Ministério da Fazenda vai depender do valor de mercado dos ativos [...]. (RÁDIO GAÚCHA, 26. jan. 2017).
}

Na sequência, o apresentador comenta: "A decisão não é do governo do estado, a decisão é da população gaúcha, porque tem que fazer plebiscito 
para decidir sobre a venda do Banrisul" (RÁDIO GAÚCHA, 26. jan. 2017). Imediatamente, o repórter Mateus Ferraz volta a participar, sem precisar ser chamado pelo apresentador. Como se estivesse entrando em uma conversa, complementa com repercussões das redes sociais, misturando opiniões de terceiros com as suas próprias considerações a respeito:

E deputados ligados ao PMDB, Macedo e Mazui, já se posicionaram através do Twitter. Por exemplo, Gilberto Capoani disse que votaria contra caso esse assunto chegasse à Assembleia. Mesmo com a Sulgás, a CEEE e a CRM, que teriam um pouco menos de resistência... Dificilmente o governo vai conseguir derrubar o plebiscito. O Banrisul, então, precisaria de uma força, de um prestígio político que a base aliada, que o governo, o Piratini não tem aqui no estado. (RÁDIO GAÚCHA, 26. jan. 2017).

O apresentador completa, opinando: "E não há motivo algum para vender o Banrisul. Essa é que é a verdade. Vende o Banrisul, torra o dinheiro ali adiante e fica sem o Banrisul e com crise financeira igual [...]. Essa história de vender o Banrisul tem outros interesses aí" (RÁDIO GAÚCHA, 26. jan. 2017).

Já no Chamada Geral - Primeira Edição de 27 de fevereiro de 2018, o repórter Eduardo Paganella entra no ar ao vivo, utilizando o Acesse relatando uma carreata de motoristas ligados ao transporte por aplicativo. O repórter começa citando o nome do apresentador e segue com informações atualizadas sobre o congestionamento provocado pela manifestação. A participação dura 46 segundos e é restrita à fala do próprio Paganella:

Macedo, manifestação que começou há pouco... Os motoristas saíram do largo da Epatur, na Loureiro da Silva, e vão se deslocar por diversos pontos na região central da capital. Já há lentidão, neste momento, em alguns pontos da Loureiro da Silva e, também, na Setembrina com Garibaldi e trechos da Farrapos. Manifestação que deve se estender até o final desta manhã, vai passar ainda pela Mauá, Bento Martins, Duque de Caxias, João Pessoa. até chegar na região do Gasômetro. O grupo é contrário à proposta que será discutida amanhã, na Câmara dos Deputados, em Brasília, que prevê mudanças na regulamentação dos aplicativos. Segundo os condutores, essa proposta vai inviabilizar o serviço de transporte de aplicativo no país. (RÁDIO GAÚCHA, 27 fev. 2018). 


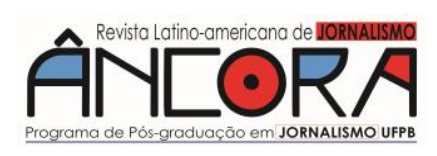

Léo Henrique SABALLA JÚNIOR - Luiz Artur FERRARETTO

Nos três exemplos descritos, predomina o bate-papo. A reportagem gravada, atualmente é uma excepcionalidade no Chamada Geral. Segundo o repórter Mateus Ferraz (16 fev. 2017), mesmo quando ocorre uma entrevista gravada passível de ser veiculada, a orientação é buscar informalidade na fala, como se estivesse improvisando, sem a assinatura do repórter ao final da participação.

\section{Considerações finais}

As alterações na reportagem da Gaúcha podem ser interpretadas como resultado de "uma demanda por novas estruturas narrativas, multimidiáticas e multiplatafor-mas que ampliam o conteúdo". (KISCHINHEVSKY, 2016, p. 105). Mesmo limitado pela ausência de programas arquivados na íntegra no acervo da emissora, o cruzamento de dados qualitativos e quantitativos demonstra a passagem para um modelo mais coloquial de narrativa. Observe-se para tanto os números da Tabela 2:

Tabela 2: Quantitativo da participação de repórteres e comentaristas no Chamada Geral

\begin{tabular}{|c|c|c|c|c|}
\hline DATA & $\begin{array}{c}\text { PARTICIPAÇÃO } \\
\text { DA } \\
\text { REPORTAGEM }\end{array}$ & $\begin{array}{c}\text { REPÓRTERES } \\
\text { AO VIVO }\end{array}$ & $\begin{array}{c}\text { REPETIÇÃO DE } \\
\text { REPORTER } \\
\text { NO MESMO } \\
\text { PROGRAMA }\end{array}$ & $\begin{array}{c}\text { COMEN } \\
\text { TARIST } \\
\text { AS }\end{array}$ \\
\hline 26.02 .1993 & 8 & $4(50 \%)^{10}$ & 1 & 3 \\
\hline 28.02 .2007 & 14 & $3(21 \%)$ & 5 & 1 \\
\hline 26.02 .2018 & 22 & $21(95 \%)$ & 7 & 0 \\
\hline
\end{tabular}

Fonte: elaboração própria

Destaca-se o aumento da participação da reportagem em 2018, com o amplo espaço para as entradas ao vivo (95\%), o que confirma a hipótese levantada ao longo deste artigo. A única inserção gravada ocorreu por uma

${ }^{10}$ Percentuais sobre a quantidade de inserções de repórteres.

João Pessoa - Brasil | ANO 7 VOL.7 N.1 | JAN./JUN. 2020 | p. 19-38 
impossibilidade da repórter, que estava desempenhando uma outra atividade ao mesmo tempo, de acordo com a editora do programa, Mariana Ceccon (27 fev. 2018). Também não há, em 2018, o recurso ao uso de comentaristas, abrindo mais espaço para a reportagem.

A predominância do ao vivo vai ao encontro de uma maior busca por instantaneidade, ampliando algo que sempre foi característico do jornalismo radiofônico. Apenas para lembrar, décadas atrás, De Felice destacava:

A principal característica de um programa de radiojornalismo é o imediatismo, a instantaneidade, a possibilidade de se levar ao ouvinte um fato simultaneamente ao acontecimento ou com diferença de minutos. Por isso, devem sempre ter precedência sobre os demais assuntos aqueles que tenham acontecido $\mathrm{HOJE}$, que estejam acontecendo HOJE ou que ainda estejam previstos para acontecer HOJE. (DE FELICE, 1981, p.88).

Outras inferências são possíveis a partir do descrito na Tabela 3. Por exemplo, reforça-se a ideia de desaparecimento de ilustrações ou sonoras e da assinatura do repórter. Basta observar a edição com data de 26 de fevereiro de 2018.

Tabela 3: Quantitativo de uso dos elementos básicos da reportagem no Chamada Geral

\begin{tabular}{|c|c|c|}
\hline \multirow{2}{*}{ DATA } & \multicolumn{2}{|c|}{ REPORTAGENS } \\
\cline { 2 - 3 } & Com ilustração ou sonora & Com assinatura \\
\hline 26.02 .1993 & $2(25 \%)$ & $6(75 \%)$ \\
\hline 28.02 .2007 & $3(21 \%)$ & $13(93 \%)$ \\
\hline 26.02 .2018 & $0(0 \%)$ & $0(0 \%)$ \\
\hline
\end{tabular}

Fonte: elaboração própria

Tem-se consciência que a amostra é reduzida, como destacado, em função da inexistência de acervo com edições integrais do programa. No entanto, o demonstrado pelos números vai ao encontro das impressões dos próprios profissionais envolvidos nesse processo. Cabe observar que: 


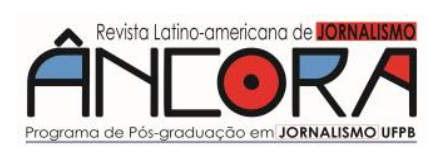

\section{Léo Henrique SABALLA JÚNIOR - Luiz Artur FERRARETTO}

(1) as alterações na forma de apresentação da reportagem no Chamada Geralsão marcadas por uma crescente coloquialidade;

(2) a reportagem gravada e editada desaparece no processo, perdendo-se, de um lado, aquela "forma aperfeiçoada" (PORCHAT, 1989, p. 54) já citada anteriormente, mas se ganhando agilidade na difusão das informações no rádio e no transbordamento dessas para redes sociais;

(3) perdem relevância aqueles elementos - cabeça, ilustração ou sonora, passagem, encerramento e assinatura - comuns até a fase de segmentação;

(4) na fase de convergência, pode-se aventar, a reportagem ganha, portanto, graças à predominância do ao vivo, um caráter ainda mais autentificante(JOST, 2001), potencializando o efeito de real (MOTTA, 2013) do que é noticiado;

\section{Referências}

BARBEIRO, Heródoto.; LIMA, Paulo Rodolfo de. Manual de radiojornalismo. 2.ed. Rio de Janeiro: Campus, 2003. BRITTOS, Valério Cruz. A televisão no Brasil, hoje: a multiplicidade da oferta. Comunicação \& Sociedade, São Bernardo do Campo: Universidade Metodista de São Paulo, ano 20, n. 31, p. 9-34, 1999. BRITTOS, Valério Cruz. O rádio brasileiro na fase da multiplicidade da oferta. Verso \& Reverso, São Leopoldo: Editora da Unisinos, ano 16, n. 35, p. 31-54, jul.-dez. 2002.

CLAUDIO MORETTO. Funcionário da Gaúcha de 1980 a 2015, tendo desempenhado, entre outras, as funções de editor do Chamada Geral, chefe de reportagem e coordenador de jornalismo. Entrevista pessoal em 20 de janeiro de 2017.

DANIEL SCOLA. Editor-chefe da Gaúcha e âncora dos programas Gaúcha Atualidade e Chamada Geral - Segunda Edição. Entrevista pessoal em 12 de janeiro de 2017.

DE FELICE, M. Jornalismo de rádio. Brasília: Thesaurus, 1981.

FERRARETTO, Luiz Artur. Comunicador radiofônico. In: ENCICLOPÉDIA INTERCOM DE COMUNICAÇÃO. São Paulo: Sociedade Brasileira de Estudos Interdisciplinares da Comunicação, 2010. v. 1, p. 312-3 (Dicionário Brasileiro do Conhecimento Comunicacional). CD-ROM. 
FERRARETTO, Luiz Artur. Uma proposta de periodização para a história do rádio no Brasil. Eptic - Revista de Economia Política das

Tecnologias da Informação e Comunicação, Aracaju: Observatório de Economia e Comunicação da Universidade Federal de Sergipe, v. XIV, n. 2, maio-ago. 2012.

FERRARETTO, Luiz Artur. Da segmentação à convergência, apontamentos a respeito do papel do comunicador de rádio. Comunicação \&

Sociedade, São Bernardo do Campo: Universidade Metodista de São Paulo, v. 36, n. 1, 2014a, p. 59-84.

FERRARETTO, Luiz Artur. Rádio: teoria e prática. São Paulo: Summus, 2014b.

FERRARETTO, Luiz Artur. Inquietudes e tensionamentos: pistas para a compreensão do rádio comercial em sua fase de convergência. Intexto, Porto Alegre: Universidade Federal do Rio Grande do Sul, n. 34, p. 214235, set.-dez. 2015.

FERRARETTO, Luiz Artur. A autentificação da realidade pelo radiojornalismo: pistas para a compreensão do papel do âncora, do comentarista e do repórter no século 21. In: ROSÁRIO, N.M. do; SILVA, A. (Org.). Pesquisa, comunicação, informação. Porto Alegre: Sulina, 2016. p. 147-163.

\section{FERRARETTO, Luiz Artur; KOPPLIN, Elisa. Técnica da redação}

radiofônica. Porto Alegre: Sagra-DC Luzzatto, 1992.

FRANCISCO PAULO BISOGNO. Funcionário da Gaúcha de 1978 a 2006, tendo desempenhado, entre outras, as funções de operador de externas e coordenador. Entrevista pessoal em 21 de janeiro de 2017.

GAÚCHA. Há 60 meses, a rádio mais ouvida. Zero Hora, Porto Alegre, 1415 mar. 2020. p. 43. Anúncio.

GONÇALVES, Carlos. Radiojornal. In: MOURA, Mario de (Org.)

Introdução à técnica radiofônica. Rio de Janeiro: Páginas, 1956. p. 29-45.

JOST, François. La télévision du quotidien: entre realité et action. Bruxelles: De Boeck, 2001.

JENKINS, Henry. Cultura da convergência. São Paulo: Aleph, 2009. KISCHINHEVSKY, Marcelo. Rádio e mídias sociais: mediações e interações radiofônicas em plataformas digitais de comunicação. Rio de Janeiro: Mauad, 2016.

KLÖCKNER, Luciano. A notícia na Rádio Gaúcha: orientações básicas sobre texto reportagem e produção. Porto Alegre: Sulina, 1997. KLÖCKNER, Luciano. A edição radiofônica no Brasil: aspectos históricose técnicos. In: FELIPPI, A.; SOSTER, D. de A.; PICCININ, F. (Org.). Edição 


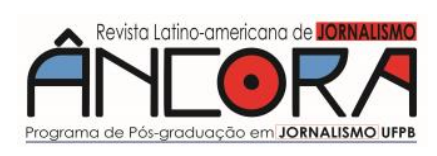

Léo Henrique SABALLA JÚNIOR - Luiz Artur FERRARETTO

em jornalismo: ensino, teoria e prática. Santa Cruz do Sul: Editora da Unisc, 2006. p. 78-95.

McLEISH, Robert. Produção de rádio: um guia abrangente de produção radiofônica. 4.ed. São Paulo: Summus, 1999.

MARIANA CECCON. Produtora da Gaúcha. Entrevista pessoal em 27 de fevereiro de 2018.

MATEUS FERRAZ. Repórter da Gaúcha. Entrevista pessoal em 16 de fevereiro de 2017.

MOSCO, Vincent. The political economy of communications: rethinking and renewal. Londres: Sage, 1996.

MOTTA, Luiz Gonzaga. Análise crítica da narrativa. Brasília: Editora Universidade de Brasília, 2013.

OZIRIS MARINS. Funcionário da Gaúcha de 1991 a 2006, tendo desempenhado, entre outras, as funções de produtor, repórter e apresentador. Entrevista pessoal em 20 de janeiro de 2017.

PICCININ, Fabiane; ETGES, Ananda; BORGES, Natany. Das narrativas de real e suas autenticações na hipertelevisão: notas sobre os programas $O$ mundo segundo os brasileiros e Não conta lá em casa. In: Encontro Nacional de Pesquisadores em Jornalismo, 13, 2015, São Paulo. Anais... Campo Grande: Associação Brasileira de Pesquisadores em Jornalismo. PORCHAT, Maria Elisa. Manual de radiojornalismo Jovem Pan. 2.ed. São Paulo: Ática, 1989.

RÁDIO GAÚCHA. Normas de produção, redação e apresentação. Porto Alegre, 1987.

RÁDIO GAÚCHA. Chamada Geral. Porto Alegre, 27 nov. 1986.

Fragmento de programa de rádio.

RÁDIO GAÚCHA. Chamada Geral - Primeira Edição. Porto Alegre, 26 fev. 1993. Fragmento de programa de rádio.

RÁDIO GAÚCHA. Chamada Geral - Primeira Edição. Porto Alegre, 28 fev. 2007. Programa de rádio.

RÁDIO GAÚCHA. Chamada Geral - Primeira Edição. Porto Alegre, 26 fev. 2018. Programa de rádio.

SCHNEIDER, S.; SCHIMITT, C.J. O uso do método comparativo nas

Ciências Sociais. Cadernos de Sociologia, Porto Alegre, v. 9, p. 49-87, 1998.

SCHUDSON, Michael. Enfoques históricos a los estudios de la Comunicación. In.: JENSEN, Klaus Bruhn; JANKOWSKI, Nicholas W. (Ed). Metodologias cualitativas de investigación en comunicación de masas. Barcelona: Bosch, 1993. p. 211-228. 